\title{
Affective Contingencies in the Affiliative Domain: Physiological Assessment, Associations With the Affiliation Motive, and Prediction of Behavior
}

Article in Journal of Personality and Social Psychology · September 2014

DOI: $10.1037 /$ pspp 0000025

CITATIONS

10

5 authors, including:

Michael Dufner

University of Leipzig

30 PUBLICATIONS 192 CITATIONS

SEE PROFILE

\section{Birk Hagemeyer}

Friedrich Schiller University Jena

21 PUBLICATIONS 74 CITATIONS

SEE PROFILE

\section{Ruben Arslan}

Georg-August-Universität Göttingen

4 PUBLICATIONS 23 CITATIONS

SEE PROFILE 
Affective Contingencies in the Affiliative Domain: Physiological Assessment, Associations with the Affiliation Motive, and Prediction of Behavior

\author{
Michael Dufner \\ University of Leipzig \\ Ruben C. Arslan \\ Georg-August University Göttingen \\ Birk Hagemeyer \\ Friedrich Schiller University Jena \\ Felix D. Schönbrodt \\ Ludwig-Maximilians-Universität München
}

Jaap J. A. Denissen

Tilburg University

To appear in Journal of Personality and Social Psychology

September 16th 2014, preprint (original article has not yet been published)

Copyright: American Psychological Association (http://www.apa.org/pubs/journals/psp/index.aspx)

This article may not exactly replicate the final version published in the APA journal. It is not the copy of record. 


\begin{abstract}
According to classical motive disposition theory, individuals differ in their propensity to derive pleasure from affiliative experiences. This propensity is considered a core process underlying the affiliation motive and a pervasive cause of motivated behavior. In this study, we tested these assumptions. We presented participants with positive affiliative stimuli and used electromyography (EMG) to record changes in facial muscular activity that are indicative of subtle smiling. We were thus able to physiologically measure positive affect following affiliative cues. Individual differences in these affective contingencies were internally consistent and temporally stable. They converged with affiliation motive self- and informant-reports, and picture story exercise (PSE) scores, indicating that they are partly accessible to the self, observable to outsiders and overlap with implicit systems. Finally, they predicted affiliative behavior in terms of situation selection and modification across a wide variety of contexts (i.e., in daily life, the laboratory, and an online social network). These findings corroborate the long-held assumption that affective contingencies represent a motivational core aspect of affiliation.
\end{abstract}

Keywords:

Motive Dispositions, Affiliation, EMG, Physiology, Implicit Motives 
The desire for positive interpersonal contact is deemed a universal human need (e.g., Baumeister \& Leary, 1995; Deci \& Ryan, 1985; Maslow, 1958). Yet, there is also a longstanding research tradition emphasizing individual differences in affiliative motives (Atkinson, Heyns, \& Veroff, 1954; McClelland, 1987; Murray, 1938). According to classical motive disposition theory, individuals differ in their tendency to derive pleasure from affiliative experiences (McClelland, 1987). The functional underpinnings of motive dispositions are seen as positive $a$ ffective contingencies (PAC). Applied to the affiliation domain (PAC-AFF), this means that if an individual has positive affiliative experiences then he or she will experience positive affect. Such affective contingencies are considered core processes underlying the affiliation motive: The more rewarding affiliative experiences are for a person (in terms of positive affect), the more he or she should desire them dispositionally (McClelland, Koestner, \& Weinberger, 1989; McAdams \& Constantian, 1983; Schultheiss, 2008).

Although the affiliation motive is rooted in an innate universal tendency to derive pleasure from experiences of close contact, individual differences in PAC-AFF might result from learning experiences. Depending on the extent to which seeking contact with others is rewarded or punished (especially in early childhood) people learn to associate affiliative situations with more or less intense positive affective consequences (McClelland 1987, McClelland \& Pilon, 1983). Novel situations become associated with positive affect if they afford pleasurable affiliative experiences. By such conditioning processes, an affectively toned associative network of situational cues and instrumental behaviors, centered around the positive experience of contact, develops and determines the strength of the affiliation motive (McClelland, 1987; see also Kuhl, 2001 for an elaborated account of the network character of motives).

Yet, even though motive disposition theory builds upon individual differences in affective contingencies, to our knowledge no research has directly probed these contingencies. Do 
individuals indeed differ in their tendency to derive pleasure out of affiliative experiences? To what extent is this tendency captured by existing affiliation motive measures? What is the relation between PAC-AFF and motivated behavior? These are the questions we addressed in the current research.

\section{The Assessment of PAC-AFF}

As expected from McClelland's (1987) theory of motives and demonstrated by research on evaluative conditioning (e.g., De Houwer, Thomas, \& Baeyens, 2001), affective reactions to enforcing situations can carry over to cues that are related to them. This means that not only genuinely affiliative experiences (i.e., experiences involving warm and close contact with others), but also conditioned stimuli, such as associated situational features, should evoke positive affective reactions. Accordingly, a PAC-AFF measure might be derived by presenting individuals with positive social stimuli (e.g., in the form of pictures or video recordings of friendly social interactions) and assessing their immediate affective responses.

But what could such an immediate measure of affective responses be? We argue that it might be possible to capture individuals' facial expressions as a proxy for their affective experience. The experience of positive emotions is accompanied by distinctive spontaneous and largely automatic facial reactions (Ekman, 1992; Tomkins, 1962). Positive emotional states typically go along with increased activity of the zygomaticus major (the muscle that elevates the corners of the mouth) and decreased activity of the corrugator supercilii (the muscle that knits the eyebrows; Cacioppo, Petty, Losch, \& Kim, 1986; Larsen, Norris, Cacioppo, 2003). This activity pattern is characteristic of human smiling. Even though such changes in facial muscular activity are often very subtle, they can be reliably captured using electromyography (EMG; Cacioppo et al., 1981; Tassinary \& Cacioppo, 2007). Hence, it should be possible to obtain a relatively direct PAC-AFF measure by assessing 
individuals' immediate zygomaticus and corrugator contractions in response to positive affiliative cues.

Initial evidence links motive-relevant experiences to facial EMG activity. The power motive, assessed via picture story exercise (PSE), has been linked to increased corrugator activity (more eyebrow knitting) in response to confrontations with assertive others (Fodor, Wick, \& Hartsen, 2006) and also to increased corrugator activity in response to negative audience reactions to an impromptu speech (Fodor \& Wick, 2009). These findings indicate that situations that threaten one's dominance appear to be particularly aversive for individuals high in the need for power. In a study by Kordik, Eska, and Schultheiss (2012), individuals high in the affiliation motive, again assessed via PSE, reacted with increased corrugator activity during conversations with persons who did not smile, but kept a neutral facial expression. This finding might indicate that speaking to an unresponsive interaction partner is aversive to individuals with a strong affiliation motive.

Taken together, these results suggest that motive-relevant experiences are accompanied by affective reactions that can be captured via EMG and that these reactions may be moderated by existing motive measures. Inspired by such findings, we aimed for a fundamentally different goal. Unlike previous research, we did not view EMG activity as an operant reaction that can be predicted by the PSE. Instead, we used EMG as a tool to derive an immediate, and purely affective motive indicator. In other words, we are the first to use EMG not as a dependent variable, but as a means to tap into individual differences in the strength of the affiliation motive.

\section{PAC-AFF and Alternative Affiliation Motive Measures}

Given that affective contingencies represent a core aspect of the affiliation motive, positive associations should exist between PAC-AFF and other assessments of individual differences in the strength of the affiliation motive. Four alternative affiliation motive indicators are self-reports, 
informant-reports, PSE-based measures, and the implicit association test (IAT). For each of these measures, we will investigate whether and to what extent an overlap with PAC-AFF is expected.

Most people are motivated (Sedikides \& Strube, 1997; Trope, 1982) and to a certain extent able (Back \& Vazire, 2012) to find out about themselves across many personality and ability domains. It seems likely that this is also true for PAC-AFF, and there are at least two possible mechanisms that could account for a positive link between PAC-AFF and the self-reported affiliation motive. First, it is possible that individuals are able to directly infer the situational contingencies underlying their emotional reactions. In this case, individuals high in PAC-AFF would notice their tendency to respond with high levels of positive affect in affiliative situations and then conclude that they have a strong affiliation motive. In line with this possibility, previous studies have shown that people have a tendency to form stable and partly accurate mental representations about situational contingencies underlying their affective responses (Denissen \& Penke, 2008). Alternatively, it is also possible that PAC-AFF is linked to the display of specific affiliative behavioral cues (see below for a thorough discussion of this point) and that these cues are then correctly interpreted as indicators of a high affiliation motive (Funder, 1995). In either case, the result would be a positive overlap between PAC-AFF and the self-reported affiliation motive.

Informants are also in many cases able to draw correct inferences about a target person's personality. Again, there are multiple mechanisms that could account for a positive link between PAC-AFF and the informant-reported affiliation motive. Two mechanisms are very similar to the ones just outlined for the self-reported affiliation motive. First, it is possible that peers directly observe target persons' emotional reactions and then draw correct inferences about underlying affective contingencies. Such a process seems possible, as PAC-AFF should go along with potentially observable facial expressions of joy in the company of others (Ekman, 1999). Second, it seems likely that peers are also able to interpret typical affiliative behaviors triggered by PAC-AFF 
as instances of the affiliation motive (Funder, 1995). A third possibility would be that that target persons communicate their emotional reactions to affiliative experiences to their peers verbally. Again, in either case, PAC-AFF should be positively linked to the informant-rated affiliation motive.

Affective contingencies are considered central to the two implicit motive measures, the PSE and the IAT. The PSE requests participants to invent stories in response to picture cues that are then content-coded for the occurrence of motivational themes (Schultheiss \& Pang, 2007). The IAT is a reaction time-based measure that assesses the differential strengths of associations between affiliative target pictures and positive attributes like nice, pleasant, or great (Slabbinck, De Houwer, van Kenhove, 2012). Both measures, the PSE and the IAT, are assumed to capture affective contingencies that are manifested in associative networks (Schultheiss \& Schultheiss, 2014; Slabbinck, et al., 2014). Accordingly, PAC-AFF should be positively related to each of them.

\section{PAC-AFF and Motivated Behavior}

Several theorists have proposed that affective contingencies are a major cause of motivated behavior (McClelland, 1987; Schultheiss, 2008; Toates, 1994). After all, a person who takes much pleasure out of affiliative experiences (i.e., who is high in PAC-AFF) should seek to maximize the probability of such experiences to occur. He or she can do so in at least two ways.

First, the person can select situations or stimuli that involve affiliative experiences (McClelland, 1980). Situations differ in their potential to gratify specific needs and should therefore be differently appealing, depending on individuals' preferences (Edwards, Caplan, \& Harrison, 1998). This means that for the person who is high in PAC-AFF, situations that involve positive social interactions should be much more appealing than for a person low in PAC-AFF. As a consequence, the person should actively seek such situations (McAdams, Healy, \& Krause, 1984; McAdams, Jackson, \& 
Kirshnit, 1984).

A second way to maximize affiliative reward is to modify a specific situation once it has been entered. If a person who is high in PAC-AFF has entered a situation that potentially entails affiliative experiences, the person will execute behaviors that will bring about such experiences with much vigor and energy (McClelland, 1987; McClelland et al., 1989). For example, if the person interacts with a stranger, he or she might engage in socializing behavior or disclose personal information in order to create a warm and affiliative social bond with the interaction partner.

\section{The Current Research}

The goal of the present investigation was to address the classic notion that affective contingencies underlie individual differences in motive dispositions. For this purpose, we examined (a) whether individuals indeed reliably differ in the levels of PAC-AFF (as indicated by EMG measurements), (b) how PAC-AFF relates to theoretically related indices of the affiliation motive (self-report, informant report, IAT, and PSE), and (c) whether it is predictive of motivated behavior in terms of situation selection and modification. Aiming for an unbiased and comprehensive test, we implemented a multi-method approach.

To derive a physiology-based PAC-AFF measure, we presented participants with stimuli displaying positive affiliative situations and assessed facial muscular activity in response. We proposed that individuals high in PAC-AFF exhibit a muscular pattern characterized by increased zygomaticus and decreased corrugator activity. We tested whether this pattern can be reliably captured using EMG and whether scores are rank-stable across time. We also argued that PAC-AFF results in observable behaviors that can be picked up by both individuals themselves and external observers. Therefore, we hypothesized that PAC-AFF would produce significant levels of convergence with affiliation motive self-reports and informant-reports. Furthermore, we assumed 
that PAC-AFF is linked to implicit associative networks and would thus correlate with PSE and IAT assessments. Finally, we investigated the link between PAC-AFF and extraversion.

Extraversion is a personality trait characterized by a tendency to approach social situations (McCrae \& John, 1992) and it has been reasoned that a pronounced sensitivity for social rewards represents a central motivational aspect of the construct (Denissen \& Penke, 2008; Depue \& Colins, 1999; Gray, 1981; Morrone, Depue, Scherer, \& White, 2000). Hence, we hypothesized a positive link between PAC-AFF and extraversion.

Regarding affiliative behavior, we focused on aspects of situation selection and modification. We predicted that PAC-AFF is linked to the selection of affiliative situations and stimuli, as these potentially entail positive affiliative experiences. To test this prediction, we assessed the frequency of situations involving affiliative experiences in everyday life using daily diary reports. In addition, we assessed participants' movie preferences, which have also been used as indicators of situation selection in previous research (Bresin \& Robinson, 2014). By watching movies, individuals can experience emotional states similar to the ones brought about by actual first-hand motivational experiences (McClelland \& Kirshnit, 1988; Schultheiss, Wirth, \& Stanton, 2004). Romantic movies by definition have affiliative content and typically depict positive affiliative experiences, such as scenes showing intimate and warm interactions between romantic partners. Comedy movies also typically involve positive social interactions. Therefore, we hypothesized that PAC-AFF is linked to a preference for romantic and comedy movies.

Regarding situation modification, we assumed that PAC-AFF is a positive predictor of behavior motivated to bring about affiliative experiences. To test this proposal, we again relied on daily diary assessments and captured individuals' progress towards self-set affiliative goals. We hypothesized that PAC-AFF is positively linked to goal progress. In addition, we assessed participants' behavior during a standardized dyadic interaction in the laboratory. Specifically, we focused on socializing 
and self-disclosure behavior, which both represent means to create a positive affiliative bond with one's interaction partner (Perlman \& Fehr, 1987; Reis \& Patrick, 1996; Reis \& Shaver, 1988; Laurenceau, Barrett, \& Pietromanaco, 1998) and have been linked to the affiliation motive in previous research (McAdams, Healy, et al. 1984; McAdams, Jackson, et al., 1984). Accordingly, we hypothesized that PAC-AFF is a positive predictor of these two types of behavior. Finally, we analyzed participants' Facebook profiles. In online social networks, such as Facebook, individuals can freely create their profile according to their preferences. Social networks thus offer a prime opportunity for studying situation modification. We hypothesized that PAC-AFF is positively linked to the amount of affiliative content in individuals' Facebook profiles.

In addition, we investigated sex differences in PAC-AFF. According to Wood and Eagly's (2002) biosocial model, people form gender role beliefs by observing the activities of men and women in their societies and receive rewarding feedback when their behavior matches these beliefs. For example, given that women perform more childcare than men in most societies, women are believed to be more nurturing and caring, and a woman whose behavior corresponds with this role belief will be regarded more positively than a woman for whom this is not the case. In such cases, through reinforcement processes women should learn to a greater extent than men to associate affiliative behavior with positive affective consequences. As a consequence, PAC-AFF should be higher among women than among men. In line with this possibility, research has shown that typically women score higher than men on the self-reported (e.g., Wong \& Csikszentmihalyi, 1991) and the PSE-assessed affiliation motive (Hagemeyer \& Neyer, 2012; McAdams, Lester, Brand, McNamara, \&Lensky, 1988; Pang \& Schultheivss, 2005; Schultheiss \& Brunstein, 2001; Stewart \& Chester, 1982).

\section{Method}




\section{Participants and Design}

Data collection took place as part of a large-scale investigation on motive dispositions. ${ }^{1}$ The study contained two waves of data collection, which were approximately 14 months apart $(M=$ 61.86 weeks, $S D=6.43$ ). At each wave, the study contained (a) online questionnaires, (b) a laboratory session, (c) a 14-day daily-diary assessment period, and (d) informant ratings. For reasons of brevity, we display some methodological details in appendices. Internal consistencies and retest-correlations are shown in Appendix A.

Participants were university students from different universities in Berlin, Germany and nearby cities. These students were working on their final study thesis at Wave 1 (the project included an investigation of the predictors of the subsequent transition to the working force). An approximately representative selection across study domains was obtained (Statistisches Bundesamt, 2011). Yet, we did not allow psychology students to participate, as they might have been familiar with many of the measures.

At Wave 1, 209 participants began with the study, and 191 of them again participated at Wave 2 (91\% retention). At both Wave 1,93\% of participants completed all study parts (parts a to d from above), at Wave 2, $85 \%$ of participants completed all parts. Participants' mean age was 27.48 $(S D=3.07)$ and $66 \%$ were females.

We asked participants to invite at least three informants who knew them well and who would be willing to provide ratings about the target at each wave. Fifty-nine per cent of informants were friends, $20 \%$ were relatives, $18 \%$ were romantic partners, and $3 \%$ were acquaintances. We asked participants to invite the same informants at both waves. As incentives, participants received monetary compensation (120 Euros) and feedback about their personality. At the end of the study, they were thanked and debriefed. The Humboldt-University's institutional review board approved 
the collection of the data used in this study.

\section{Laboratory Sessions}

Laboratory procedure. There was one laboratory session at each wave. During each session, we assessed EMG activity in response to affiliative stimuli, explicit ratings of enjoyment during stimulus presentation, and an affiliation IAT. The sessions took place in a lit room, where the experimenter (research assistants or interns of both sexes who were approximately of the same age as the participants) welcomed each participant, seated him or her in a comfortable chair and attached the EMG electrodes. To safeguard unbiased recordings, the experimenter told the participants that the electrodes measured skin conductance (participants were debriefed after the second wave). Throughout the whole session, a small webcam filmed participants from the front, which participants were aware and consenting of. To allow the electrodes to reach a stable baseline, participants initially watched a relaxing video with neutral content (an unpopulated beach scene). Stimulus presentation, the IAT, and tasks irrelevant for the current purpose appeared in randomized order at the center of a computer screen $(40 \mathrm{~cm} \times 26 \mathrm{~cm})$ approximately 80 centimeters in front of the participants. At Wave 2, the laboratory session contained a structured interaction to observe participants' behavior that was filmed by the webcam. The content of this interaction is described in Appendix B.

EMG assessments and explicit judgments of task enjoyment. We recorded muscular activity of the zygomaticus major and the corrugator supercilii on the left side of the face. We did so by placing two electrodes to the corresponding muscle sites in accordance with the guidelines by Fridlund and Cacioppo (1986) and one forehead electrode as common reference (technical details on the EMG recording procedure can be found in Appendix B). The signal was rectified and withinperson z-standardised for each muscle. The purpose of this standardization was to minimize the 
influence of potentially confounding factors, such as thickness of skin or distance between the electrodes, which would otherwise have added to noise variance in the measurements. Hence, high values at a given time point indicated that muscle contraction was high in comparison to the mean level of muscle contraction over the whole laboratory session. The computation of the PAC-AFF individual difference scores will be described in the Results section.

As affiliative stimuli, we used pictures with positive affiliative content, such as a group of friends eating pizza together, or a family going for a walk together. ${ }^{2}$ We also had pictures available displaying positive achievement-related content (e.g., a college student holding her diploma) and positive power-related content (e.g., a politician waving to a crowd). We used these pictures as control stimuli to rule out the possibility that a general proclivity for smiling in response to positive stimuli (irrespective of the motive domain) accounts for any effects.

We conducted an online study to test the validity of our stimuli. Twenty-six undergraduate students and research assistants $(65 \%$ females, mean age $=23.04, S D=4.98)$ rated for each picture to what extent it contained affiliation- (affiliation and intimacy), achievement- (achievement and performance), and power-related (power and control) content $(1=$ does not have to do with it at all, to 4 = has a lot to do with it). We used a within-person within subject ANOVA and tested the interaction between picture domain (affiliation-related pictures, achievement-related pictures, power-related pictures) and content ratings (affiliation ratings, achievement ratings, power ratings). This interaction was significant $F(2,4)=506.71, p<.001$, and Appendix C demonstrates that motive content ratings were always highest for the according picture class.

At Wave 1, we presented four pictures from each motive domain. At Wave 2, we presented these same pictures, but also a random selection of additional pictures that were drawn from a larger pool (Fiedler, 2011). These were 11 positive affiliative pictures, and on average participants saw four of 
them (hence, on average, participants saw eight pictures in total at Wave 2). Each picture was preceded by a fixation cross (which appeared for one second) and remained on the screen for four seconds. After each picture had been presented, participants judged the extent to which they had experienced positive emotions ("I had positive feelings while watching this picture"; $1=$ do not agree at all to $5=$ agree totally). To examine the temporal dynamics of the pictures' effects on muscular activity (see Results section), we aggregated EMG activity across all pictures and participants separately for each second of picture presentation.

Implicit association test. We implemented a self-developed affiliation IAT using the computer program Inquisit (2005). As target stimuli, participants saw either pictures with positive affiliative content (e.g., a friendly gathering) or negative affiliative content (e.g., a person being socially excluded). These pictures were partly the same as the ones used for the EMG assessments. The IAT consisted of seven blocks (cf. Greenwald, Nosek, \& Banaji, 2003), and we used the $D_{l}$ indicator as a measure of implicit affiliation. Trials with latencies $>10,000 \mathrm{~ms}$ were excluded. As recommended by Greenwald et al. (2003), we used both the combined task practice blocks and the test blocks to compute reliabilities and the total IAT score.

Video-observed behavior. Three independent observers coded participants' behavior during the structured interaction in terms of socializing and self-disclosure behavior. A full list of all coded cues (including indicators of inter-rater agreement) is provided in Appendix D. All codings were made on a five-point scale $(1=$ never occurs/don't agree at all to $5=$ occurs very often/strongly agree). The cues indicative of socializing behavior were taken from earlier research (Argyle \& Dean, 1965; Coker, \& Burgoon, 1987; Brunner, 1979; Deutsch, LeBaron, \& Fryer, 1987; Graham

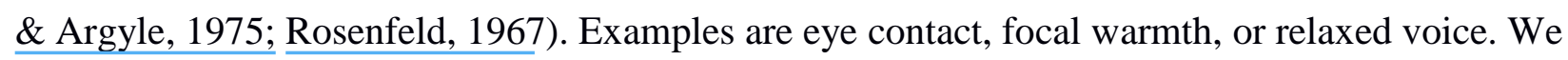
formed a composite score by aggregating across all cues $($ alpha $=.80)$. The cues indicative of selfdisclosure behavior were taken from the Self-Disclosure Coding System (SDCS, Chelune, 1976). 
This system assesses different aspects of self-disclosure, such as the quantity of information disclosed, or the intimacy of the verbal content. We used a shortened form of this system and supplemented it by one item assessing the extent to which the observers had the impression that they know the participant after having seen him or her interact. We formed a composite by aggregating across all cues (alpha $=.89$ ).

Facebook content. At the end of the Wave 2 laboratory session, the experimenter asked participants whether they had a Facebook profile and if this was the case $(n=150)$, whether they were willing to download parts of it on a laboratory computer ( $n=59$, see Appendix B for details). Two independent observers then coded indicators of affiliation, such as the relative amount of pictures showing the participant in the company of other people or the frequency of positive posts about others $(1=$ never occurs/very atypical to $5=$ occurs very often/very typical $)$. All cues (including indicators of inter-rater agreement) are shown in Appendix D. We formed an affiliation composite score by aggregating across all cues (alpha $=.62)$.

\section{Online Questionnaires}

Self-reported affiliation motive. We assessed the self-reported affiliation motive at both waves aggregating the standardized scores of several affiliation motive scales. These were the affiliation scale from the Personality Research Form (PRF, Jackson, 1967; German version by Stumpf, Angleitner, Wieck, Jackson, \& Beloch-Till, 1985), the affiliation and intimacy scales from the Unified Motives Scales (UMS-10, Schönbrodt \& Gerstenberg, 2012), and a self-developed affiliation motive scale (see Appendix B for further information).

Self-reported extraversion. We used a validated short form of the German Big Five Inventory (BFI-K, Rammstedt \& John, 2005) to assess extraversion.

Informant-reported affiliation motive. At both waves, we measured the informant-reported 
affiliation motive using the affiliation and intimacy subscales of a short form of the UMS (the UMS-3, Schönbrodt \& Gerstenberg, 2012) and our self-developed affiliation motive scale. We computed an interrater-agreement via ICC for average measures. The mean ICC, averaged across all measures and the two waves (using Fisher's $z$-transformation), was .57. Again, we computed an affiliation composite score by averaging standardized scores.

Movie preferences. At Wave 2, participants were requested to enter the titles of their five favorite movies into an open text field ${ }^{3}$. Research assistants then looked up these movies using the website IMDB. At this website, classification categories were displayed for a given movie (e.g., romance, comedy, drama, etc.). Whenever movies fell into more than a single category, multiple categories were scored. The research assistants coded the frequency of each classification category for each participant. We focused our analyses on popular movie categories that occurred at least once for at least 30 per cent of participants (e.g., drama, romance).

\section{Daily Diary Assessments}

At both waves, participants were requested to fill out questionnaires on 14 days between $6 \mathrm{pm}$ and 4 am and received a daily e-mail reminder to do so.

Picture story exercise. We used the standard instructions described by Pang and Schultheiss (2005), presented one picture each day to participants (14 pictures in total), and gave them five minutes for each story. Information on the picture cues is provided in Appendix B.

Several trained coders scored the PSE stories using the Winter (1994) system (four coders at Wave 1 and two coders at Wave 2). Each coder worked independently on a distinct subset of stories. Based on 93 stories, we computed absolute inter-coder agreement using a two-way random ICC. The ICC was .92 at Wave 1 and .93 at Wave 2. We partialled out each story's word count and omitted entries that were nonsensical or included statements of noncompliance, such as, for 
example "Today, I have no interest in writing a story" (59 stories at Wave 1 and 71 stories at Wave 2).

Affiliative situations. To assess the daily occurrence of affiliative situations, we asked participants to judge the extent to which certain events had occurred during the present day. These events were (a) spending time with someone they like very much, (b) having a good talk with someone close, and (c) spending much time with one's partner, friends or family $(1=$ don't agree at all to $5=$ agree very much). At each wave, these scores were aggregated across the 14 days and the three scores were then aggregated to a composite. Cronbach's alpha was .81 at Wave 1 and .85 at Wave 2. The retest correlation across the two waves was $r=.48, p<.001$.

Progress Towards Affiliative Goals. On the first day of the daily diary period, participants identified two goals from the domain "affiliation and social contact" that were personally relevant for them and that they were willing to work on during the upcoming two weeks. Each day, participants rated for each goal the extent to which they had progressed towards it by using five items. Sample items are "I made a lot of progress towards this goal today", and "I didn't get far today in the pursuit of my goal" (reverse scored) $(1=$ don't agree at all to $5=$ agree very much). Further details are provided in Appendix B. We computed a progress score based on all items from the two goals (Cronbach's alpha was .81 at Wave 1 and .85 at Wave 2). Then, we aggregated across the 14 days for each Wave. The retest correlation was $r=.35, p<.001$.

\section{Results}

Our analyses focused the three major research questions described in the Introduction. We first analyzed whether it is possible to reliably capture individual differences in PAC-AFF from physiology (a). Then, we went on to investigate the associations between PAC-AFF and existing affiliation motive measures (b). As a third step, we tested whether PAC-AFF is predictive of 
affiliative behavior in terms of situation selection and modification (c). In cases when variables had been assessed at both waves, we aggregated scores across the waves to increase reliability and solely interpret these aggregated effects (for reasons of comprehensibility, however, all correlations within and across waves are shown in Table 1).

\section{Computation of the PAC-AFF Score and its Reliability}

To explore general effects of stimulus presentation on EMG activity, we aggregated muscular activity across each full second following affiliative picture presentation. We then used a two-factor repeated measures ANOVA with muscle as the first factor (zygomaticus vs. corrugator) and time as the second factor (second after picture presentation; 0-1000 ms, 1001-2000 ms, 2001-3000 ms, $3001-4000 \mathrm{~ms})$. There was a main effect of muscle, $F(1,206)=85.13, p<.001$, indicating that zygomaticus activity was higher than corrugator activity during stimulus presentation. There was no significant effect of time, $F(2.23,458.33)=0.63, p=.61$, but a significant muscle $\mathrm{x}$ time interaction, $F(2.203,453.81)=33.13, \mathrm{p}<.001$. As shown in Figure 1, one second after stimulus presentation, activity increased for zygomaticus and decreased for corrugator activity and then remained at approximately the same level. Hence, in line with our expectation, we detected changes in muscular activity that are indicative of positive affect. For each muscle, we aggregated muscular activity from $1001 \mathrm{~ms}$ to $4000 \mathrm{~ms}$ after stimulus onset (the time period when the expected pattern of activity was present). To control for baseline muscular activity, we partialled out baseline activity from mean activity during picture presentation. Baseline-corrected zygomaticus activity was negatively correlated to corrugator activity at Wave $1, r=-.28, p<.001$, and Wave $2, r=-.42, p<$ .001. As positive affective experience is accompanied by both increases in zygomaticus and decreases in corrugator activity (Cacioppo et al., 1986), we computed PAC-AFF scores by subtracting corrugator activity from zygomaticus activity at each wave ${ }^{4}$. 
Thus far, the findings indicated that on average, participants had a tendency to display facial muscular activity indicative of joy in response to positive affiliative stimuli. Our next question was whether the PAC-AFF individual difference scores derived through the procedure described above are internally consistent and stable across time. To compute internal consistency, we subtracted baseline-corrected corrugator activity from baseline-corrected zygomaticus activity for each picture for both waves. At Wave 2 we could not use Cronbach's alpha owing to the random selection of stimuli presented. Therefore, we computed the ICC for average measures using lme4 (Bates, Maechler, Bolker, Walker, 2013), which is conceptually equivalent to an alpha score. The ICC was .61 at Wave 1 (alpha was also .61) and .85 at Wave 2. The higher internal consistency at Wave 2 is likely due to the larger number of stimuli. The temporal stability of the PAC-AFF score across the two waves was $r=.42, p<.001$. In total, these findings indicate that individual differences in PACAFF were captured with acceptable to good reliability and were moderately stable across time.

As a validation check, we investigated the correlation between PAC-AFF and self-reported positive emotions during stimulus presentation. As expected, this correlation was positive at Wave $1, r=.20, p<.001$, and at Wave $2, r=.27, p<.001$. This means that individuals with high PACAFF scores indeed reported to have experienced positive emotions during stimulus presentation. Yet, the relatively weak strength of the correlation also indicated that PAC-AFF additionally tapped into affective reactions that were either too subtle for participants to notice or that they were unwilling to acknowledge. This validated our choice to use EMG assessment as a way to circumvent these constraints.

\section{Associations with Affiliation Motive Indicators and Extraversion}

We then went on to investigate associations between PAC-AFF and several affiliation motive indicators. We had assumed that PAC-AFF is a core aspect of the affiliation motive that is 
positively linked to all other affiliation motive indicators. As shown in Table 1, PAC-AFF indeed correlated positively with self-reports, informant-reports, and also several positive correlations with the PSE score were present. ${ }^{5}$ Hence, PAC-AFF was linked to what participants themselves thought about their affiliation motive, to their close peers' representations of their affiliation motive, and to motive-relevant semantic contingencies, as assessed with the PSE. The only measure that was uncorrelated to PAC-AFF was the IAT. PAC-AFF was thus linked to the majority of alternative affiliation motive measures. Also in line with our expectation, PAC-AFF was positively linked to extraversion.

\section{Prediction of Affiliative Behavior}

Thus far, we have detected individual differences in PAC-AFF which could be reliably assessed and were linked to affiliation motive measures. In our next step, we tested whether PAC-AFF is able to predict affiliative behavior. Specifically, we focused on aspects of stimulus or situation selection and situation modification. First, we investigated situation selection. We had argued that individuals high in PAC-AFF should seek positive affiliative experiences and therefore select situations that potentially entail such experiences. As shown in Table 1, PAC-AFF was positively linked to the frequency of positive affiliative situations across 14 days in the daily diary assessments. This means that the higher individuals were on PAC-AFF, the more they tended to enter situations involving positive affiliative experiences in their everyday lives. Also in line with our hypotheses, PAC-AFF was linked to a preference for movies involving positive affiliative content. As shown in Table 1, PAC-AFF was related to liking romances and comedies, as well as to disliking science fiction movies. Taken together, the findings indicate that PAC-AFF is indeed linked to the choice of situations and stimuli that entail affiliative experiences.

Then, we investigated the links between PAC-AFF and situation modification. We had argued 
that PAC-AFF is positively linked to the display of behavior that potentially leads to the attainment of rewarding affiliative experiences. To test this assumption, we investigated goal progress in daily life, interaction behavior in the laboratory, and Facebook profile content. We had hypothesized, and indeed found, that PAC-AFF was a positive predictor of progress towards affiliative goals (see Table 1). Concerning interaction behavior in the laboratory, we had hypothesized that PAC-AFF is a positive predictor of socializing and self-disclosure behavior. In line with our assumption, PACAFF indeed positively predicted both socializing and self-disclosure behavior in the laboratory (see Table 1). Finally, we had hypothesized that PAC-AFF was predictive of affiliative profile content on Facebook, and again, this was indeed the case (see Table 1). Hence, the findings from the daily diary assessments, behavioral codings from the laboratory, and Facebook content codings, uniformly supported the hypothesis that PAC-AFF is predictive of motivated situation modification.

\section{Sex Differences}

In a final step, we investigated sex differences. We had hypothesized that women score higher on PAC-AFF than men. In line with this hypothesis, women had higher PAC-AFF scores aggregated across the two waves, $t(180.83)=2.38, p=.02, d=.35$.

\section{Supplementary Analyses}

As a test of discriminant validity, we investigated the associations between PAC-AFF and measures of the achievement or power motive that were also included in our dataset. In analogy to the computations for the affiliation motive measures, we computed composite scores for self- and informant-reports based on the achievement or power subscales of the PRF, UMS, and our selfdeveloped instrument. We again aggregated all motive measures across the two waves. Findings revealed that PAC-AFF was not significantly related to achievement motive self-reports, $r=.03, p$ $=.67$, informant-reports, $r=.07, p=.33$, PSE, $r=.08, p=.27$, or IAT, $r=.00, p=.97$. Similarly, 
PAC-AFF was uncorrelated to power motive self-reports, $r=.12, p=.10$, informant-reports, $r=$ $.05, p=.50$, PSE, $r=.07, p=.33$, or IAT, $r=-.02, p=.81$. These findings demonstrate that PACAFF was specifically linked to measures of the affiliation motive, and not to measures of the achievement or power motive.

As a test of incremental validity, we further investigated for each outcome whether associations persist when covariates are controlled. Specifically, we ran a series of regression analyses and entered affiliation motive self-report, informant-report, PSE, IAT, extraversion, or sex as additional predictors (in each analysis, we controlled for one additional affiliation measure at a time). A significant effect would indicate that PAC-AFF predicts affiliative outcomes above and beyond alternative affiliation measures. In addition, we used explicit enjoyment during stimulus presentation as a covariate to test whether the EMG-based PAC-AFF measure incrementally predicts outcomes above and beyond self-reported affect. Then, we controlled for EMG activity during the presentation of achievement and power cues. If the effects of PAC-AFF remained significant, this would rule out the alternative explanation that they are driven by a motiveunspecific tendency to respond with positive affect to positively valenced stimuli. ${ }^{6}$ As shown in Table 2, predictions of PAC-AFF remained significant or marginal in the vast majority of cases (92\%), regardless of which covariate we controlled for. This confirms the incremental validity of PAC-AFF over established motive measures.

Finally, we investigated whether sex moderated associations between PAC-AFF and affiliation motive measures or behavioral outcomes. We did so by simultaneously predicting each of these variables by PAC-AFF, sex, and their interaction. The interaction term was significant in the case of affiliative situations in everyday life $(\beta=.16 p=.04$; prediction for women: $\beta=.17, p=.05$, prediction for men: $\beta=.33, p=.004)$ and self-disclosure behavior $(\beta=-.25, p=.01$; prediction for women: $\beta=.31, p=.004$, prediction for men: $\beta=-.27, p=.10)$. Nevertheless, the fact that only for 
two out of 13 variables interaction effects were significant indicates that sex was overall not a consistent moderator.

\section{Discussion}

The aim of the current study was to address the long-held assumption that individuals differ in their tendency to derive pleasure out of affiliative experiences. We captured facial expressions in response to affiliative cues as a proxy for this tendency and by this means derived a straightforward and immediate measure of PAC-AFF. Our analyses focused on three major goals. First, we tested whether PAC-AFF indeed varies between individuals and can be reliably inferred from physiology. Second, we investigated the associations between PAC-AFF and different affiliation motive measures. Third, we tested whether PAC-AFF is predictive of affiliative behavior in terms of situation selection and modification. We will discuss each of these three points in the following.

We detected a general tendency to react with facial muscular activity indicative of joy in response to positive affiliative cues. This result is convergent with universalist theories positing a generally rewarding nature of affiliative experiences. Crucially however, there were systematic individual differences in this tendency, and these could be reliably captured. The internal consistency of our PAC-AFF measure was high, especially at Wave 2 when it involved additional picture cues. In fact, the internal consistency was comparable with self-reported instruments, which seems notable given that PAC-AFF was measured in a purely physiological fashion. Moreover, the considerable temporal stability over a 14-month time interval clearly demonstrates that not only fleeting situational variance was captured, but rather a trait-like construct. The size of the retest correlation approximates the upper bound of what is reported for indirect personality measures in the literature (Egloff, Schwerdtfeger, \& Schmukle, 2005). These findings demonstrate that individuals indeed systematically differ in their spontaneous tendency to respond with subtle 
displays of joy in response to affiliative cues, and that this tendency can be reliably captured. We were thus able to assess a feature of the affiliation motive that has been considered central since the early days of motive disposition theory_affiliative contingencies—in a straightforward and purely physiological fashion. To the best of our knowledge, this is the first demonstration that physiological data derived from facial muscular activity can be used to measure an aspect of personality.

We detected positive links to several indicators of the affiliation motive. PAC-AFF was linked to the self-rated affiliation motive. This finding matches well with earlier research reporting modest, but nevertheless reliable self-insight capabilities into aspects of personality (Back \& Vazire, 2012). It indicates that individuals are either able to draw correct abstract inferences about the situational contingencies underlying their emotional reactions or that they are capable of correctly interpreting behavioral cues triggered by PAC-AFF as indicators of the affiliation motive.

PAC-AFF was also positively linked to the informant-rated affiliation motive. Hence, not only target persons themselves, but also well-acquainted informants are able to judge PAC-AFF above chance levels, most likely by correctly interpreting behavioral displays of joy, affiliative behaviors, or speech content. Interestingly, the overlap between PAC-AFF and informant-reports was not larger than the one between PAC-AFF and self-reports (descriptively, it was even smaller). A larger overlap for informant-reports would have been expected if PAC-AFF was a personality trait that is highly observable from the outside, such as, for example, extraversion (Vazire, 2010). Hence, PAC-AFF seems to be partly, but not highly observable from the outside.

Moreover, PAC-AFF was positively linked to the affiliation PSE score. Even though the correlation of the scores that were aggregated across the waves was only marginally significant at the .06 level, several significant correlations within and across the waves indicate that a moderate 
positive association exists. This result converges with McClelland's (1987) proposal that affective contingencies underlie the implicit affiliation motive as assessed through the PSE. It seems likely that the PSE indeed to a certain extent captures affective contingencies that have been manifested in the associative network. As we have used a somewhat unusual approach for the assessment of the PSE to capitalize on the principle of aggregation (14 instead of six pictures, daily assessment of one story), we consider it possible that the association could be higher with a PSE score assessed through the standard procedure.

The only measure that was uncorrelated to PAC-AFF was the affiliation IAT. Yet, little is known about the validity of the affiliation IAT, especially of the newly developed version used in this study. Therefore, it is possible that the null correlation with PAC-AFF might be due to impaired validity of the IAT. Regardless, the overall results pattern of positive links between PAC-AFF and all established affiliation motive measures (i.e., self-report, informant-report, PSE) clearly support our proposal that PAC-AFF is a core aspect of the affiliation motive.

In line with our expectation, PAC-AFF was also positively linked to self-reported extraversion. This finding indicates that extraversion involves a spontaneous tendency to respond with positive affect to positive social stimuli that is evident at a physiological level (Depue \& Collins, 1999), and that it shares this tendency with the affiliation motive. This result provides an indirect support for the notion that extraverts might by characterized by heightened sensitivity for social rewards.

The litmus test for the validity of PAC-AFF pertains to the prediction of real behavior. Strongly supporting our hypotheses, we detected associations between PAC-AFF and aspects of situation selection and modification. PAC-AFF was positively predictive of affiliative situation selection in everyday life and of a preference for movies with affiliative content (i.e., romantic movies and comedies). Even though the disliking of science fiction movies was not hypothesized, it fits well 
into the picture. Science fiction movies typically involve little affiliative content and should therefore be dreary for individuals high in PAC-AFF. In all, these findings provide convergent support for the assumption that PAC-AFF is linked to the selection of affiliative situations and stimuli (McClelland, 1987).

In addition, PAC-AFF was linked to aspects of situation modification. PAC-AFF was predictive of progress towards self-set affiliative goals as well as to socializing and self-disclosure behavior in the laboratory. These results are convergent with previous PSE-based studies (McAdams, Healy et al., 1984; McAdams, Jackson, et al., 1984). The finding that PAC-AFF was linked to affiliative Facebook profile content demonstrates that traces of affiliative situation modification can be found in an individuals' virtual leisure environment. In all, these results indicate that individuals high in PAC-AFF possess a pervasive tendency to alter their environment in ways that increase the frequency of positive interpersonal contacts and potentially lead to the formation of social bonds.

As the results on situation selection and modification demonstrate, PAC-AFF is a major predictor of affiliative behavior across a wide variety of domains. We implemented several key methods for the assessment of behavior ranging from daily diary assessments to direct observation in the laboratory (Furr, 2009) and could rule out the alternative explanation that results are due to general responsivity to positive stimuli. We regard this as the most direct evidence available thus far in support of the claim that domain-specific affective contingencies are an important and pervasive cause of motivated behavior (McClelland, et al., 1989; Schultheiss, 2008). A possible step for future research might be to establish a stringent test of causality, for example by investigating whether trainings or therapeutic interventions can lead to increases in PAC-AFF and whether these increases account for future affiliative behavior.

We investigated, and found, sex differences. In line with our hypothesis, PAC-AFF was higher 
for women than for men. This sex difference stands in line with earlier findings demonstrating higher affiliation motive scores for women than for men (Hagemeyer \& Neyer, 2012; McAdams et al., 1988; Pang \& Schultheiss, 2005; Schultheiss \& Brunstein, 2001; Stewart \& Chester, 1982) and therefore represents a final piece of evidence supporting the validity of the PAC-AFF indicator. Women indeed respond with more pronounced positive affect to affiliative cues than men, and it is possible that this tendency partly accounts for sex differences in affiliative behavior. Based on Wood and Eagly's (2002) biosocial model, it seems even possible that PAC-AFF represents a developmental link between individuals' gender specific social reinforcement histories and subsequent changes in affiliative behavior. Future research might address these possibilities.

One practical contribution of the current research is that it introduces a novel methodology for the assessment of the affiliation motive. Regarding its content validity, the EMG-based PAC-AFF measure corresponds very well with McClelland's (1987) description of the implicit affiliation motive as affect-based, unconscious, nonverbally represented, and predictive of spontaneous behavior. The measure builds upon spontaneous physiological reactions to visual stimuli and is positively linked to the major implicit motive measure (the PSE) as well as to spontaneous behavior in a wide variety of contexts. PAC-AFF was also related to self-reported motives and therefore indirectly links otherwise unconnected implicit and explicit measures of the affiliation motive. Importantly, it predicted affiliative outcomes incrementally above and beyond all alternative measures. This indicates that PAC-AFF transcends the established differentiation of implicit and explicit motives and captures key aspects of the affiliation motive that have not been covered yet. We are convinced that these aspects should not be neglected in future research.

From a broader perspective, the principle introduced here might be transferred to other personality domains. Affective contingencies are also assumed to underlie the achievement and the power motive (McClelland et al., 1989). Moreover, there are approaches describing other 
personality traits such as, for example the other four of the Big Five personality traits (Denissen \& Penke, 2008), or narcissism (Morf \& Rhodewalt, 2001) as if-then contingencies between specific classes of situations and affective reactions. In all these cases, it may be possible to derive indirect measures by presenting individuals with trait-relevant visual cues and assessing the facial reactions indicative of a certain trait-specific emotional reaction via EMG. We encourage future researchers to address this possibility.

\section{In Closing}

In all, the current research indicates that affiliative behavior cannot be fully explained by universalist approaches towards affiliation alone. Hedonic reactivity to affiliative cues is a central component of the affiliation motive and a pervasive predictor of affiliative behavior across many contexts. It appears like affiliation indeed makes some people happier than others and exactly for this reason, some—but not all—of us spend their days seeking the contact of others. 


\section{Funding}

This research was supported by a grant from the German Research Foundation (Deutsche

Forschungsgemeinschaft, DFG), allocated to Jaap J. A. Denissen (grant number: DE-1662/2-1). 


\section{References}

Argyle, M., \& Dean, J. (1965). Eye-contact, distance and affiliation. Sociometry, 28, 289-304. doi: $10.2307 / 2786027$

Atkinson, J. W., Heyns, R. W., \& Veroff, J. (1954). The effect of experimental arousal of the affiliation motive on thematic apperception. Journal of Abnormal and Social Psychology, 49, 405-410. doi:10.1037/h0053499

Back, M. D. \& Vazire, S. (2012). Knowing our personality. In S. Vazire \& T. D. Wilson (Eds.) Handbook of Self Knowledge (pp. 131-156). New York: Guilford

Bates, D., Maechler, M., Bolker, B., \& Walker, S. (2013). lme4: Linear mixed-effects models using Eigen and S4. R package version 1.0-5. http://lme4.r-forge.r-project.org/

Baumeister, R. F., \& Leary, M. R. (1995). The need to belong: desire for interpersonal attachments as a fundamental human motivation. Psychological Bulletin, 117, 497-529. doi:10.1037/00332909.117.3.497

Blanton, H.,Jaccard, J., Gonzales, P. M., \& Christie, C. (2006). Decoding the implicit association test: Implications for criterion prediction. Journal of Experimental Social Psychology, 42, 192212. doi:10.1016/j.jesp.2005.07.003

Bresin, K., \& Robinson, M. D. (2014). You Are What You See and Choose: Agreeableness and Situation Selection. Journal of Personality. Advance online publication. doi: 10.1111/jopy.12121

Brunner, L. J. (1979). Smiles can be back channels. Journal of Personality and Social Psychology, 37, 728-734. doi:10.1037/0022-3514.37.5.728

Cacioppo, J. T., Petty, R. E., Losch, M. E., \& Kim, H. S. (1986). Electromyographic activity over 
facial muscle regions can differentiate the valence and intensity of affective reactions. Journal of Personality and Social Psychology, 50, 260-268. doi:10.1037/0022-3514.50.2.260

Chelune, G. J. (1975). Studies in the behavioral and self-report assessment of self-disclosure. (Doctoral dissertation). Retrieved from Dissertation Abstracts International, 37 (453B).

Coker, D. A., \& Burgoon, J. (1987). The nature of conversational involvement and nonverbal encoding patterns. Human Communication Research, 13, 463-494. doi:10.1111/j.14682958.1987.tb00115.x

Deci, E. L., \& Ryan, R. M. (1985). Intrinsic motivation and self-determination in human behavior. New York, NY: Plenum. doi:10.1007/978-1-4899-2271-7

De Houwer, J., Thomas, S., \& Baeyens, F. (2001). Association learning of likes and dislikes: A review of 25 years of research on human evaluative conditioning. Psychological Bulletin, 127, 853-869. doi:10.1037/0033-2909.127.6.853

Denissen, J. J. A., \& Penke, L. (2008). Motivational individual reaction norms underlying the FiveFactor model of personality: First steps towards a theory-based conceptual framework. Journal of Research in Personality, 42, 1285-1302. doi:10.1016/j.jrp.2008.04.002

Depue, R. A., \& Collins, P. F. (1999). Neurobiology of the structure of personality: Dopamine, facilitation of incentive motivation, and extraversion. Behavioral and Brain Sciences, 22, 491517.

Deutsch, F. M., LeBaron, D., \& Fryer, M. M. (1987). What is in a smile? Psychology of Women Quarterly, 11, 341-352.

Edwards, J.R., Caplan, R. D., \& Harrison, R.V. (1998). Person-environment fit theory: Conceptual foundations, empirical evidence, and directions for future research. In C. L. Cooper (Ed.), Theories of organizational stress (pp. 28-67). Oxford: Oxford University Press. 
Egloff, B., Schwerdtfeger, A. \& Schmukle, S. C. (2005). Temporal stability of the Implicit Association Test-Anxiety. Journal of Personality Assessment, 84, 82-88. doi: 10.1207/s15327752jpa8401_14

Ekman, P. (1992). An argument for basic emotions. Cognition \& Emotion, 6, 169-200. doi: $10.1080 / 02699939208411068$

Ekman, P. (1999a). Basic emotions. In T. Dalgleish \& T. Power (Eds.), The handbook of cognition and emotion (pp. 45-60). Sussex, GB: John Wiley \& Sons.

Ekman, P. (1999). Basic emotions. Handbook of cognition and emotion, 4, 5-60.

Fiedler, K. (2011). Voodoo correlations are everywhere-not only in neuroscience. Perspectives on Psychological Science, 6, 163-171. doi:10.1177/1745691611400237

Fodor, E. M., \& Wick, D. P. (2009). Need for power and affective response to negative audience reaction to an extemporaneous speech. Journal of Research in Personality, 43, 721-726. doi:10.1016/j.jrp.2009.06.007

Fodor, E. M., Wick, D. P., \& Hartsen, K. M. (2006). The power motive and affective response to assertiveness. Journal of Research in Personality, 40, 598-610. doi:10.1016/j.jrp.2005.06.001

Fridlund, A. J., \& Cacioppo, J. T. (1986). Guidelines for human electromyographic research. Psychophysiology 23, 567-589. doi:10.1111/j.1469-8986.1986.tb00676.x

Funder, D. C. (1995). On the accuracy of personality judgment: a realistic approach. Psychological Review, 102, 652-670. doi:10.1037/0033-295X.102.4.652

Furr, R. M. (2009). Personality psychology as a truly behavioural science. European Journal of Personality, 23, 369-401. doi:10.1002/per.724

Graham, J. A., Bitti, P. R., \& Argyle, M. (1975). A cross-cultural study of the communication of 
emotion by facial \& gestural cues. Journal of Human Movement Studies, 1. 68-77.

Gray, J. A. (1970). The psychophysiological basis of introversion-extraversion. Behaviour Research and Therapy, 8, 249-266. doi:10.1016/0005-7967(70)90069-0

Greenwald, A. G., Nosek, B. A., \& Banaji, M. R. (2003). Understanding and using the implicit association test: I. An improved scoring algorithm. Journal of Personality and Social Psychology, 85, 197-216. doi:10.1037/0022-3514.85.2.197

Hagemeyer, B., \& Neyer, F. J. (2012). Assessing implicit motivational orientations in couple relationships: The Partner-Related Agency and Communion Test (PACT). Psychological Assessment, 24, 114-128. doi:10.1037/a0024822

Heckhausen, H. (1963). Hoffnung und Furcht in der Leistungsmotivation [hope and fear in achievement motivation]. Meisenheim am Glan, Germany: Anton Hain.

Inquisit 2.0. [Computer software]. (2005). Seattle, WA: Millisecond Software LLC.

Jackson, D. N. (1967). Manual for the Personality Research Form. Goshen, IN: Research Psychologist Press.

Kordik, A.,Eska, K., \& Schultheiss, O. C. (2012). Implicit need for affiliation is associated with increased corrugator activity in a non-positive, but not in a positive social interaction. Journal of Research in Personality, 46, 604-608. doi:10.1016/j.jrp.2012.05.006

Kuhl, J. (2001). Motivation und Persönlichkeit. Interaktionen psychischer Systeme [Motivation and personality. Interactions of mental systems]. Göttingen, Germany: Hogrefe.

Larsen, J. T., Norris, C. J., \& Cacioppo, J. T. (2003). Effects of positive and negative affect on electromyographic activity over zygomaticus major and corrugator supercilii. Psychophysiology, 40, 776-785. doi:10.1111/1469-8986.00078 
Laurenceau, J.-P., Barrett, L. F., \& Pietromonaco, P. R. (1998). Intimacy as an interpersonal process: the importance of self-disclosure, partner disclosure, and perceived partner responsiveness in interpersonal exchanges. Journal of Personality and Social Psychology, 74, 1251. doi:10.1037/0022-3514.74.5.1238

Maslow, A. H. (1958). A dynamic theory of human motivation. In C. L. Stacey \& M. DeMartino (Eds.), Understanding human motivation (pp. 26-47). Cleveland, OH: Howard Allen Publishers.

McAdams, D. P., \& Constantian, C. A. (1983). Intimacy and affiliation motives in daily living: An experience sampling analysis. Journal of Personality and Social Psychology, 45, 851-861. doi:10.1037/0022-3514.45.4.851

McAdams, D. P., Healy S., \& Krause S. (1984). Social motives and patterns of friendship. Journal of Personality and Social Psychology 47, 828-238. doi: $\underline{10.1037 / 0022-3514.47 .4 .828}$

McAdams, D. P., Jackson, R. J., \& Kirshnit, C. (1984). Looking, laughing, and smiling in dyads as a function of intimacy motivation and reciprocity. Journal of Personality, 52, 261-273. doi:10.1111/j.1467-6494.1984.tb00881.x

McAdams, D. P., Lester, R. M., Brand, P. A., McNamara, W. J., \& Lensky, D. B. (1988). Sex and the TAT: Are women more intimate than men? Do men fear intimacy? Journal of Personality Assessment, 52, 397-409.

McClelland, D. C. (1980). Motive dispositions: The merits of operant and respondent measures. Review of Personality and Social Psychology, 1, 10-41.

McClelland, D. C. (1987). Human motivation. New York, NY: Cambridge University Press.

McClelland, D. C., \& Kirshnit, C. (1988). The effect of motivational arousal through films on salivary immunoglobulin A. Psychology and Health, 2, 31-52. 
doi:10.1080/08870448808400343

McClelland, D. C., Koestner, R., \& Weinberger, J. (1989). How do self-attributed and implicit motives differ? Psychological Review, 96, 690-702.

McClelland, D. C., \& Pilon, D. A. (1983). Sources of adult motives in patterns of parent behavior in early childhood. Journal of Personality and Social Psychology, 44, 564-574. doi:10.1037/0022-3514.44.3.564

McCrae, R. R., \& John, O. P. (1992). An introduction to the five-factor model and its applications. Journal of personality, 60, 175-215. doi: 10.1111/j.1467-6494.1992.tb00970.x

Morf, C. C., \& Rhodewalt, F. (2001). Unraveling the paradoxes of narcissism: A dynamic selfregulatory processing model. Psychological Inquiry, 12, 177-196. doi:10.1207/S15327965PLI1204_1

Morrone, J. V., Depue, R. A., Scherer, A. J., \& White, T. L. (2000). Film-induced incentive motivation and positive activation in relation to agentic and affiliative components of extraversion. Personality and Individual Differences, 29, 199-216. doi: 10.1016/S01918869(99)00187-7

Murray, H. A. (1938). Explorations in personality. New York: Oxford University Press.

Pang, J. S., \& Schultheiss, O. C. (2005). Assessing implicit motives in US college students: Effects of picture type and position, gender and ethnicity, and cross-cultural comparisons. Journal of Personality Assessment, 85, 280-294. doi:10.1207/s15327752jpa8503_04

Perlman, D. \& Fehr, B. (1987). The development of intimate relationships. In: D. Perlman \& S. Duck (Eds.), Intimate relationships: development, dynamics, and deterioration (pp. 13-42). Newbury Park, CA: Sage.

Rammstedt, B., \& John, O. P. (2005). Kurzversion des Big Five Inventory (BFI-K) [short version of 
the Big Five Inventory]. Diagnostica, 51(4), 195-206. doi:10.1026/0012-1924.51.4.195

Reis, H. T., \& Patrick, B. P. (1996). Attachment and intimacy: Component processes. In E. T. Higgins \& A. W. Kruglanski (Eds.), Social psychology: Handbook of basic principles (pp. 523-563). New York; Guilford

Reis, Harry T., \& Shaver P. (1988). Intimacy as an interpersonal process. In S. Duck (Ed.), Handbook of personal relationships: Theory, research, and interventions (pp. 367-389). New York, NY: Wiley.

Rosenfeld, H. M. (1967). Nonverbal reciprocation of approval: An experimental analysis. Journal of Experimental Social Psychology, 3, 102-111. doi:10.1016/0022-1031(67)90040-6

Schönbrodt, F. D., \& Gerstenberg, F. X. (2012). An IRT analysis of motive questionnaires: The unified motive scales. Journal of Research in Personality. 6, 725-742. doi:10.1016/j.jrp.2012.08.010

Schultheiss, O. C. (2008). Implicit motives. In O. P. John, R. W. Robins, \& L. A. Pervin (Eds.), Handbook of personality: Theory and research (3rd ed.) (pp. 603-633). New York, NY: Guilford Press.

Schultheiss, O. C., \& Brunstein, J. C. (2001). Assessment of implicit motives with a research version of the TAT: Picture profiles, gender differences, and relations to other personality measures. Journal of Personality Assessment, 77, 71-86. doi:10.1207/S15327752JPA7701_05

Schultheiss O. C, \& Pang J. S. (2007). Measuring implicit motives. In R. W. Robins, R. C. Fraley, R. F. Krueger (Eds.), Handbook of Research Methods in Personality Psychology (pp. 323-44). New York, NY: Guilford.

Schultheiss, O. C., \& Schultheiss, M. (2014). Implicit motive profile analysis: An if-then contingency approach to the picture-story exercise. Social and Personality Psychology 
Compass, 8, 1-16. doi:10.1111/spc3.12082

Schultheiss, O. C., Wirth, M. M., \& Stanton, S. J. (2004). Effects of affiliation and power motivation arousal on salivary progesterone and testosterone. Hormones and Behavior, 46, 592-599. doi:10.1016/j.yhbeh.2004.07.005

Sedikides, C., \& Strube, M. J. (1997). Self-evaluation: To thine own self be good, to thine own self be sure, to thine own self be true, and to thine own self be better. Advances in Experimental Social Psychology, 29, 209-269. doi:10.1016/S0065-2601(08)60018-0

Slabbinck, H., De Houwer, J., \& Van Kenhove, P. (2012). The pictorial attitude implicit association test for need for affiliation. Personality and Individual Differences, 53, 838-842. doi:10.1016/j.paid.2012.06.016

Statistisches Bundesamt (2011). Bildung und Kultur: Studierende an Hochschulen, Wintersemester 2010/11 [Education and culture: University students, fall semester 2010/2011]. Wiesbaden, Germany: Statistisches Bundesamt.

Stewart, A. J., \& Chester, N. L. (1982). Sex differences in human social motives: Achievement, affiliation, and power. In: Stewart A. J. (ed.), Motivation in society (pp. 172-218). San Francisco, CA: Jossey-Bass 1982.

Stopfer, J. M., Egloff, B., Nestler, S. \& Back, M. D. (2013). Personality expression and impression formation in online social networks: An integrative approach to understanding the processes of accuracy, impression management and meta-accuracy. European Journal of Personality, $\underline{\text { advance online publication. doi:10.1037/a0028240 }}$

Stumpf, H., Angleitner, A., Wieck, T., Jackson, D. N., \& Beloch-Till, H. (1985). Deutsche Personality Research Form (PRF): Handanweisung [German personality research form: manual]. Göttingen, Germany: Hogrefe. 
Tassinary, L. G., \& Cacioppo, J. T. (2000). The skeletomotor system: Surface electromyography. In J. T. Cacioppo, L. G. Tassinary, \& G. G. Berntson (Eds.), Handbook of psychophysiology, (2nd ed., pp. 163-199). New York, NY: Cambridge University Press.

Toates F. M. (1994). Comparing motivational systems-an incentive motivation perspective. In: C.

R. Legg \& D. A. Booth (Eds.), Appetite: neural and behavioural bases (pp. 305-327). New York, NY: Oxford University Press.

Tomkins, S. S. (1962). Affect, imagery, and consciousness: The positive affects. New York, NY: Springer.

Trope, Y. (1982). Self-assessment and task performance. Journal of Experimental Social Psychology, 18, 201-215. doi:10.1016/0022-1031(82)90050-6

Van Boxtel, A. (2001). Optimal signal bandwidth for the recording of surface EMG activity of facial, jaw, oral, and neck muscles. Psychophysiology 38, 22-34. doi:10.1111/14698986.3810022

Vazire, S. (2010). Who knows what about a person? The self-other knowledge asymmetry (SOKA) model. Journal of Personality and Social Psychology, 98, 281-300. doi:10.1037/a0017908

Winter, D. G. (1994). Manual for scoring motive imagery in running text (4th ed.). Department of Psychology, University of Michigan, Ann Arbor: unpublished manuscript.

Wong, M. M., \& Csikszentmihalyi, M. (1991). Affiliation motivation and daily experience: Some issues on gender differences. Journal of personality and social psychology, 60, 154. doi: $10.1037 / 0022-3514.60 .1 .154$

Wood, W., \& Eagly, A. H. (2002). A cross-cultural analysis of the behavior of women and men: implications for the origins of sex differences. Psychological Bulletin, 128, 699. doi: 
10.1037/0033-2909.128.5.699 


\section{Footnotes}

${ }^{1}$ Only the study parts and measures that were relevant for the current research question are described here.

${ }^{2}$ The original stimulus material can be obtained from the first author.

${ }^{3} \mathrm{~A}$ minority (7\%) of participants listed either more or less than five movies. Excluding these participants did not alter the results.

${ }^{4} \mathrm{~A}$ possible disadvantage of difference scores is that they impose a dimensional reduction and a potential confound onto their components (e.g., Blanton, Jaccard, Gonzales, \& Christie, 2006). When results are found for a difference score, one does not know whether this effect is driven only by one of both components, or by some mixture of both. Therefore, we also computed models where zygomaticus and corrugator contributed as separate variables. In virtually all cases when significant effects for the difference score were present, the weights of both variables had opposite signs with a comparable size (a positive weight for zygomaticus and a negative weight for corrugator in the case of affiliative outcomes). This indicates that the difference score is a valid operationalization in this study.

${ }^{5}$ The study included an experimental manipulation that took place between Wave 1 and Wave 2 in which we provided half of participants feedback about their PSE scores from Wave 1 (including a description of what the PSE measures). As this manipulation may have affected the validity of the Wave 2 scores, we also computed the correlation between PAC-AFF and the Wave 2 PSE score based solely on data from participants who had obtained no feedback. This correlation was also positive and significant, $r=.23, p=.04$. We also explored whether the association between the PSE and PAC-AFF becomes stronger if the PSE score is computed solely based on codings of the seven pictures with the highest mean affiliation codings (bridge, nightclub, conference group, man at 
desk, trapeze artists, boy at desk, and mountaineer in our case). Correlations were not higher than the ones for the scores based on all picture codings (Wave 1: $r=-.08, p=.27$, Wave 2: $r=.15, p=$ .06 , both waves: $r=.11, p=.15)$. Furthermore, we computed the correlation based on a PSE score that only contained the codings of the first six pictures (as it may be possible that the validity of the PSE drops for larger picture sets). Again, the scores were not higher than the ones for the scores based on all picture codings (Wave 1: $r=-.09, p=.21$, Wave 2: $r=.06, p=.43$, both waves: $r=$ $.04, p=.45)$. Hence, overall the most highly aggregated PSA-score proved to be most valid.

${ }^{6} \mathrm{PAC}-\mathrm{AFF}$ correlated positively with EMG activity in response to pictures with positive achievement $(\mathrm{r}=.54, \mathrm{p}<.01)$ and power $(\mathrm{r}=.26, \mathrm{p}<.01)$ content (scores were computed in the same fashion as for affiliation). We thus explored whether the achievement and power picture based scores predicted any of the present affiliation-related outcomes and found that this was not the case. Finally, we tested whether the achievement-based score was linked to achievement motive measures and whether the power-based score was linked to power motive measures and did not find any significant results (all computations were based on scores that were again aggregated across the two waves). 


\begin{tabular}{|c|c|c|c|}
\hline Extraversion $_{\mathrm{W} 2}$ & .06 & $.21 * *$ & $.15^{\dagger}$ \\
\hline $\mathrm{EXT}_{\mathrm{BW}}$ & .11 & $.22 * *$ & $.18 *$ \\
\hline Affiliative situations $_{\mathrm{W} 1}$ & $.20 * *$ & $.24 * *$ & $.24 * *$ \\
\hline Affiliative situations ${ }_{W 2}$ & $.14^{\dagger}$ & $.17^{*}$ & $.18 *$ \\
\hline Affiliative situations $_{\mathrm{BW}}$ & $.19 * *$ & $.23 * *$ & $.25 * *$ \\
\hline Goal progressw1 & -.04 & .08 & .02 \\
\hline Goal progress ${ }_{W 2}$ & $.27 * *$ & $.23 * *$ & $.30 * *$ \\
\hline Goal progress ${ }_{\mathrm{BW}}$ & .10 & $.19^{*}$ & $.15^{*}$ \\
\hline Socializing behavior $_{\mathrm{W} 2}$ & $.32 * *$ & $.19 *$ & $.27 * *$ \\
\hline Self-disclosure behavior ${ }_{\mathrm{W} 2}$ & $.19 *$ & $.20 *$ & $.22 *$ \\
\hline Facebook content $_{\mathrm{W} 2}$ & .09 & $.41 * *$ & $.29 *$ \\
\hline Comedy $_{\mathrm{w} 2}$ & $.18^{*}$ & .10 & $.16^{*}$ \\
\hline Dramaw2 & -.05 & -.03 & -.06 \\
\hline Fantasyw2 & .00 & .00 & .00 \\
\hline Adventure $_{\mathrm{W} 2}$ & .04 & .06 & .04 \\
\hline Romance $_{\mathrm{W} 2}$ & $.23 * *$ & $.18^{*}$ & $.24 * *$ \\
\hline Crime $_{\mathrm{W} 2}$ & -.03 & .07 & .03 \\
\hline Action $_{W 2}$ & .01 & -.05 & -.01 \\
\hline
\end{tabular}


Science-Fiction $_{\mathrm{W} 2} \quad-.12 \quad-.21 * * \quad \mathbf{- . 1 9 *}$

$\begin{array}{llll}\text { Thriller }_{\mathrm{W} 2} & -.08 & .14 & \mathbf{0 5}\end{array}$

Note. $\mathrm{W} 1=\mathrm{Wave} 1, \mathrm{~W} 2=\mathrm{Wave} 2, \mathrm{BW}=$ Scores aggregated across both waves; for each index, the correlation based on the most aggregated data (i.e., the most reliable one) is written in boldface letters. ${ }^{\dagger} p<.10, * p<.05, * * p<.01$. 
Table 2. Occurrence of Positive Affiliative Situations, Progress Towards Affiliative Goals,Socializing and Self-Disclosure Behavior in the Laboratory, and Affiliative Content of Facebook Profile Predicted by PAC-AFF

\begin{tabular}{|c|c|c|c|c|c|c|c|c|c|}
\hline & & \multicolumn{8}{|c|}{ Self- } \\
\hline & & Affiliative & Goal & Socializing & disclosure & Facebook & & & Science- \\
\hline Indicator & Measure & situations & progress & behavior & behavior & content & Comedy & Romance & fiction \\
\hline Zero-order $\beta$ & PAC-AFF & $.25 * *$ & $.15^{*}$ & $.27 * *$ & $.22 *$ & $.29 *$ & $.16^{*}$ & $.24 * *$ & $-.19 *$ \\
\hline \multirow[t]{5}{*}{ Partial $\beta$} & PAC-AFF AFF_SELF $_{\text {A }}$ & $.18^{*}$ & $.14^{\dagger}$ & $.23 *$ & $.18^{*}$ & $.25^{\dagger}$ & .09 & $.19 *$ & $-.19 *$ \\
\hline & PAC- & $.25^{* *}$ & $.17 *$ & $.23 *$ & $.19 *$ & $.24^{\dagger}$ & .12 & $.20 * *$ & $-.18 *$ \\
\hline & $\mathrm{AFF}_{\text {AFF_INFORMANT }}$ & & & & & & & & \\
\hline & PAC-AFF ${ }_{\mathrm{AFF} \text { PSE }}$ & $.23 * *$ & $.14^{*}$ & $.24 * *$ & $.24 *$ & $.23^{\dagger}$ & $.16^{\dagger}$ & $.23 * *$ & $-.18 *$ \\
\hline & PAC-AFF ${ }_{\text {AFF_IAT }}$ & $.26 * *$ & $.18 *$ & $.27 * *$ & $.22 *$ & $.29 *$ & $.16^{*}$ & $.23 * *$ & $-.20 *$ \\
\hline
\end{tabular}




\begin{tabular}{|c|c|c|c|c|c|c|c|c|}
\hline PAC-AFF RATING & $.22 * *$ & $.12^{\dagger}$ & $.24^{*}$ & $.22 *$ & .19 & $.15^{\dagger}$ & $.20^{*}$ & $-.17 *$ \\
\hline PAC-AFF ${ }_{\text {ACHPOW }}$ & $.27 * *$ & $.20 *$ & $.28 * *$ & $.30 * *$ & .26 & $.24 *$ & $.23 *$ & $-.25 * *$ \\
\hline PAC- & $.25^{* *}$ & $.17 *$ & $.23^{*}$ & .13 & $.34 *$ & $.14^{\dagger}$ & $.23 * *$ & $-.18 *$ \\
\hline \multicolumn{9}{|l|}{ AFF $_{\text {EXTRAVERSION }}$} \\
\hline AC-AFF & $.22 * *$ & $.14^{*}$ & $.22 *$ & $.20 *$ & $.25^{\dagger}$ & $.13^{\dagger}$ & $.19^{* *}$ & $-.16^{*}$ \\
\hline
\end{tabular}

Note . Zero-order $=$ zero-order association, partial $=$ partial associations, $\mathrm{PAC}-\mathrm{AFF}_{\mathrm{AFF} \_\mathrm{SELF}}=$ affiliation self-report controlled, $\mathrm{PAC}-\mathrm{AFF}_{\mathrm{AFF} \_\mathrm{INFORMANT}}=$ affiliation informant-report controlled, $\mathrm{PAC}-\mathrm{AFF}_{\mathrm{AFF} \_\mathrm{PSE}}=$ affiliation PSE controlled, $\mathrm{PAC}-\mathrm{AFF}_{\mathrm{AFF} \_\mathrm{IAT}}=$ affiliation IAT controlled, $\mathrm{PAC}-\mathrm{AFF}_{\mathrm{RATING}}=$ explicit ratings of enjoyment during stimulus presentation controlled, $\mathrm{PAC}-\mathrm{AFF}_{\mathrm{ACHPOW}}=\mathrm{EMG}$ activity in response to positive achievement- and power-rated stimuli controlled, PAC-AFF $\mathrm{EXTRAVERSION}_{\mathrm{N}}=$ self-reported extraversion controlled, $\mathrm{PAC}-\mathrm{AFF}_{\mathrm{SEX}}=\operatorname{sex}$ controlled. ${ }^{\dagger} p<.10,{ }^{*} p<.05, * * p<$ .01 . 
Figure 1

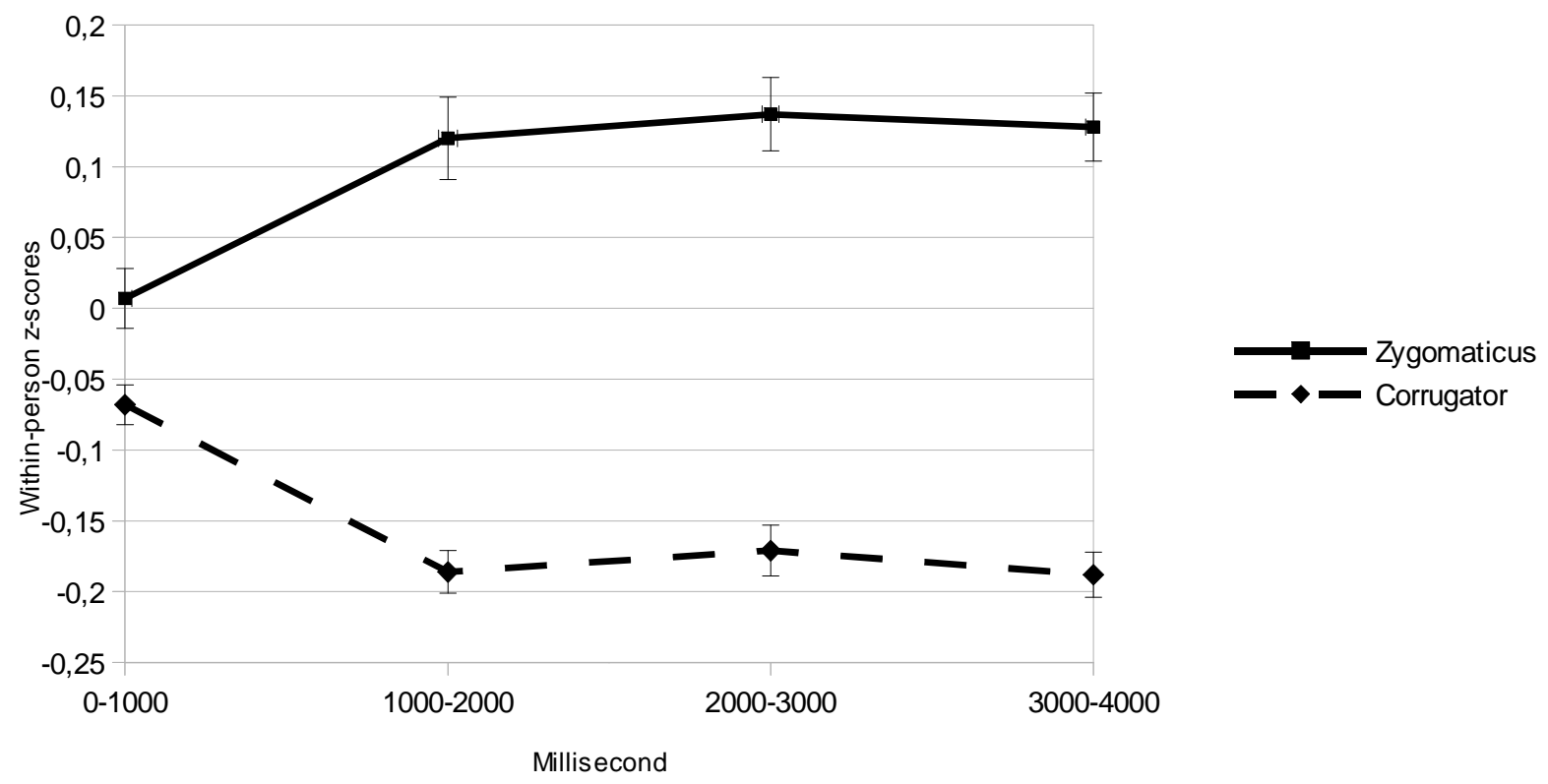

Mean zygomaticus and corrugator activity during stimulus presentation. Scores are aggregated across all affiliative pictures. 


\section{Appendix A}

Internal Consistencies and Retest-Reliabilities of Self- and Informant-Reported Affiliation Measures.

\begin{tabular}{|c|c|c|c|c|}
\hline Data source & Measure & Internal & Internal & Retest correlation \\
\hline
\end{tabular}

\begin{tabular}{|c|c|c|c|c|}
\hline \multirow[t]{3}{*}{ Self-report } & PRF & .79 & .81 & $.77 * *$ \\
\hline & $\mathrm{UMS}_{\mathrm{aff}}$ & .80 & .81 & $.70 * *$ \\
\hline & $\mathrm{UMS}_{\mathrm{int}}$ & .77 & .78 & $.64 * *$ \\
\hline & AP & .81 & .76 & $.68 * *$ \\
\hline & COMP & .71 & .76 & $.78 * *$ \\
\hline & EXT & .81 & .82 & $.84 * *$ \\
\hline \multirow[t]{4}{*}{ Informant-report } & $\mathrm{UMS}_{\mathrm{aff}}$ & .89 & .82 & $.66^{* *}$ \\
\hline & $\mathrm{UMS}_{\mathrm{int}}$ & .73 & .66 & $.64 * *$ \\
\hline & AP & .86 & .79 & $.54 * *$ \\
\hline & COMP & .64 & .66 & $.65^{* *}$ \\
\hline PSE & & .32 & .45 & $.28 * *$ \\
\hline IAT & & .57 & .55 & $.45^{* *}$ \\
\hline
\end{tabular}




\section{RUNNING HEAD: AFFILIATION AND AFFECT}

Note. In all cases except the IAT, we computed Cronbach's alpha as an indicator of internal consistency. For the IAT scores, we computed the internal consistency indicators proposed by Greenwald et al. (2003), PRF = Personality Research Form, $\mathrm{UMS}_{\mathrm{aff}}=$ Unified Motive Scales affiliation scale, $\mathrm{UMS}_{\mathrm{int}}=$ Unified Motive Scales intimacy scale, $\mathrm{AP}=$ Self-Developed Affiliation Motive Scale, $\mathrm{COMP}=$ composite score, $\mathrm{EXT}=$ Extraversion, $\mathrm{PSE}=$ Picture Story Exercise, $\mathrm{IAT}=$ Implicit Asssociation Test 


\section{Appendix B}

\section{Measurement Details}

\section{Content of the structured interaction between the experimenter and the participant. At} the end of the laboratory session, the experimenter entered the room and told the participant that he or she would have to wait for a few minutes while the computer was saving the data. Then, the experimenter started the conversation (without the participant being aware that this conversation was still a part of the study). After the conversation, participants were fully debriefed. Due to a partial malfunction of the recording device, we could only analyze data from 123 participants (68\% of participants who attended the laboratory session at Wave 2).

The experimenter asked the following questions: (1) "How did you like the experiment?", (2) “Do you feel like you have personally gained something out of participating in this study?", and (3) “Are you finished with your studies yet?". If the answer to the third question was positive, the experimenter asked (4a) "Did you start working yet, or are you still looking for a job? What is it like being in this situation?". If the answer to the third question was negative, the experimenter asked (4b) "When will you be finished with your studies? What is it like being nearly at the end of one's studies?". Finally, the experimenter asked (5) "What are your plans for the future?". The experimenter asked one question at a time and gave participants time to speak for as long as they wanted to.

Technical details of the EMG recording procedure. We used bipolar, 4-mm standard non-polarising silver/silverchloride surface electrodes. We assessed the EMG signal with a digital 'Psychlab' amplifier (Contact Precision Instruments, Boston) at a sampling frequency of $1000 \mathrm{~Hz}$ (signals were amplified x 10000). Offline, the EMG raw signal was filtered with a $30 \mathrm{~Hz}$ low cutoff filter and a $150 \mathrm{~Hz}$ high cutoff filter (van Boxtel, 2001) as well as a notch filter at $50 \mathrm{~Hz}$ to remove 
the power line hum.

Content of Facebook download. Participants were requested to download their personal profile page (containing participants' postings, and postings of other persons that were linked to participants), their personal information page (containing information provided by participants about themselves), and their personal "likes" page (containing information about things liked by participants). These pieces of information have also been used in earlier research on Facebook and personality (e.g., Stopfer, Egloss, Nestler, \& Back, 2013).

\section{Description of the scales used to assess the self- and informant-reported affiliation}

motive. The PRF is one of the most established instruments to assess self-reported motive dispositions. The UMS are new scales based on an item-response analysis of several established motive scales (i.e., affiliation, intimacy, power, achievement, and fear motive). Unlike the PRF and the UMS, which focus on the self-concept and behavioral aspects of motive dispositions, our selfconstructed affiliation motive scale focused on motive-relevant affective experiences. The scale is part of an instrument assessing individuals' extent to derive pleasure out of affiliative, achievementrelated, or power-related experiences. To generate items, we implemented a rational scale construction. We first defined the core psychological processes underlying each motive disposition and then let a team of six colleagues (five doctoral students and a student assistant) formulate corresponding items. This resulted in three scales of ten items each. Two sample items for the affiliation scale are "If another person shows me that he or she likes me, I feel really good" or "I really enjoy forming new friendships" $(1=$ does not apply at all, $5=$ fully applies $)$. To pilot the newly constructed questionnaire, we administered it to 290 internet users (69\% women) with an average age of 25 years. Items were factor analyzed and an inspection of the scree plot suggested a clear three-factor structure. After Varimax rotation, all items loaded most highly on the a-priori 


\section{RUNNING HEAD: AFFILIATION AND AFFECT}

defined factor, with only a single exception (a power item that loaded most highly on affiliation). The average primary loading was .65, against an average highest secondary loading of only .17; the differences between primary and highest secondary loadings ranged between .19 and .77 . Because of these encouraging results, items were averaged into scales, with resulting reliabilities of $.88, .81$ and .83 for power, affiliation and achievement, respectively. Scales were only moderately correlated, with the highest correlation between power and achievement, $r=.45, p<.01$. In average, participants most highly endorsed achievement items $(M=4.33, S D=.48)$, followed by affiliation $(M=4.11, S D=.49)$ and power $(M=3.58, S D=.65)$.

Information on the PSE picture cues. We used the six pictures discussed by Pang and Schultheiss (2005) that are widespread in the literature (boxer, bridge, nightclub, trapeze, laboratory, captain), six pictures from Heckhausen's (1963) achievement TAT (several men in an office, a boy sitting at a desk, a man sitting at a desk, a man in an office, a conference group, a group of workers) and two pictures showing a sports scene (a snowboarder, a mountaineer).

Information on daily affiliative goal assessment. For reasons of clarification, we provided participants with two examples of typical affiliative goals. These examples were "I want to spend more time with my friends and create positive experiences with them" and "I hope to get to know my new flat mate better". Participants subsequently typed two of their own affiliative goals into an open text field. Each day, after participants rated their goal progress, they were asked whether they had reached each one goal completely so that they did not have to work on it anymore. If this was the case, they were requested to name a new goal that they were willing to work on. Before we ran our analyses, a research assistant checked the validity of the goal entries and deleted data referring to goal entries that did not match the purported motive or were nonsensical. About $9 \%$ of all goals were deleted. 


\section{RUNNING HEAD: AFFILIATION AND AFFECT}

\section{Appendix C}

Mean Motive Content Ratings for the Affiliation-, Achievement-, and Power-Related Pictures (95

Percent Confidence Intervals are Shown in Parentheses)

\begin{tabular}{llll}
\hline Rating & Affiliation Pictures & Achievement Pictures & Power Pictures \\
\hline Affiliation & $\mathbf{3 . 8 3}(\mathbf{C I}: \mathbf{3 . 7 6 - 3 . 9 0})$ & 1.87 (CI: 1.71-2.03) & 2.06 (CI:1.85-2.27) \\
Achievement & $1.48(\mathrm{CI}: 1.37-1.60)$ & $\mathbf{3 . 8 0}$ (CI: 3.75-3.86) & 3.06 (CI: 2.91-3.21) \\
Power & $1.53($ CI: $1.39-1.67)$ & 2.46 (CI: $2.28-2.64)$ & $\mathbf{3 . 3 6}$ (CI: 3.23-3.49) \\
\hline
\end{tabular}




\section{Appendix D}

Inter-rater Agreement for Behavioral Cue Codings.

\begin{tabular}{|c|c|c|}
\hline Scale & Cue & Alpha \\
\hline \multirow[t]{8}{*}{ Socializing behavior } & Eye contact & .72 \\
\hline & Social warmth & .70 \\
\hline & Relaxed laughter & .79 \\
\hline & Nodding & .76 \\
\hline & Smiling & .76 \\
\hline & Aims to create pleasant atmosphere & .82 \\
\hline & Mentions close other people & .96 \\
\hline & Is friendly & .81 \\
\hline \multirow[t]{6}{*}{ Self-disclosure behavior } & Amount of disclosed information & .85 \\
\hline & Amount of positive disclosed information & .76 \\
\hline & Amount of negative disclosed information & .79 \\
\hline & Amount of neutral disclosed information & .42 \\
\hline & Intimacy of the verbal content & .81 \\
\hline & Verbal content and the affective manner of & .35 \\
\hline
\end{tabular}


RUNNING HEAD: AFFILIATION AND AFFECT

Impression of knowing the person

\begin{tabular}{|c|c|c|}
\hline \multirow[t]{4}{*}{ Affiliative Facebook content } & $\begin{array}{l}\text { Pictures with other people in relation to total } \\
\text { number of pictures }\end{array}$ & .85 \\
\hline & Smiling on pictures & .70 \\
\hline & Positive posts about other people & .79 \\
\hline & $\begin{array}{l}\text { Overall affiliativeness of personal information } \\
\text { page }\end{array}$ & .78 \\
\hline
\end{tabular}

